\title{
Mechanical Property Evaluation of a SLMed Martensitic Stainless Steel
}

\author{
Yun Shi ${ }^{1,2} \cdot$ Xiaojing Xiong ${ }^{3} \cdot$ Zhengwu Liu $^{1,2} \cdot$ Yi Yang $^{4} \cdot$ Juan $\mathrm{Hou}^{4} \cdot$ Songquan $\mathrm{Wu}^{4} \cdot$ Jeremy H. Rao ${ }^{5} \cdot \mathrm{Kai}_{\text {Zhang }}{ }^{4,6}$. \\ Aijun Huang ${ }^{6}$
}

Received: 17 April 2020 / Revised: 11 August 2020 / Accepted: 11 August 2020 / Published online: 4 September 2020

(c) The Chinese Society for Metals (CSM) and Springer-Verlag GmbH Germany, part of Springer Nature 2020

\begin{abstract}
A martensitic stainless steel AISI420 fabricated by selective laser melting (SLM) and post-processed by austenitizing and tempering heat treatment was investigated in this study. The as-fabricated SLMed AISI420 showed a strong mechanical property anisotropy and low ductility in the longitudinal direction. Detailed microstructural characterization revealed the presence of austenite and a relatively sharp solidification texture in the as-fabricated state, while the sharp texture was considered as the cause for the mechanical property anisotropy. In contrast, a fully martensitic microstructure with a very weak texture was achieved after the austenitizing and tempering heat treatment. The mechanical property anisotropy was also fully eliminated, witnessing a significant improvement in the ductility, and thus, comparable mechanical performance with the wrought product was achieved in this study.
\end{abstract}

Keywords Selective laser melting $\cdot$ Microstructures $\cdot$ Tensile testing $\cdot$ Electron backscattered diffraction (EBSD) . Martensitic steel

\section{Introduction}

Due to the high strength and excellent corrosion resistance, martensitic stainless steels (MSSs) with the chromium (Cr) content of more than $11 \mathrm{wt} \%$ have been widely used for components such as steam generators, offshore petroleum

Yun Shi and Xiaojing Xiong have contributed equally to this work.

Available online at http://link.springer.com/journal/40195.

Kai Zhang

kai.zhang@usst.edu.cn

1 Shanghai Aerospace Equipments Manufacturer Co., Ltd, Shanghai 200245, China

2 Shanghai Research Center of Complex Metal Parts by Additive Manufacturing, Shanghai 200245, China

3 Monash (Suzhou) Engineering Technology Co., Ltd, Suzhou 215123, China

4 School of Materials Science and Engineering, University of Shanghai for Science and Technology, Shanghai 200093, China

5 Future Industries Institute, University of South Australia, Mawson Lakes, SA 5095, Australia

6 Monash Centre for Additive Manufacturing (MCAM), Monash University, Clayton, VIC 3800, Australia platforms, valve seats and stem rods in petrochemical, marine and aerospace industries [1,2]. Fully martensitic microstructures could be achieved through austenitizing heat treatment followed by quenching, while the ductility could be restored after subsequent tempering heat treatment [3]. Through the manipulation of the heat treatment process, the mechanical properties of MSSs could be tailored accordingly [3]. However, the fabrication methods of MSSs are mostly limited to cutting and machining [4], making the manufacturing of complex MSS components with internal channels extremely difficult. In order to achieve increased functionality and buy-to-fly ratio, the improvement in structural design should also correspond to novel manufacturing methods able to fabricate complex MSS components at a lower cost.

Additive manufacturing has been successfully developed and used for many alloy systems [5, 6]. It offers more freedom to design components with higher geometrical complexity and thus could potentially increase the buyto-fly ratio at a lower cost $[5,6]$. Among all the additive manufacturing techniques, selective laser melting (SLM) method has drawn great attention due to its capability of improving dimensional accuracy, surface finish and mechanical properties [7-12]. It is a powder-based process that repeatedly melts selective regions on a coated 
thin powder layer according to a computer-aided design file to form a three-dimensional component in a layer-bylayer manner [13]. A large amount of previous work on SLMed steels, mainly stainless steel $316 \mathrm{~L}$, was conducted to achieve both high strength and ductility while maintaining good printing quality, including low defect levels $[14,15]$. The cooling rate in SLM could be more than $5 \times 10^{4} \mathrm{~K} / \mathrm{s}$ [6], leading to non-equilibrium solidification in the as-fabricated state. For instance, in SLMed stainless steels, ultra-fine cellular and dendritic structures with high residual stress can be obtained in as-fabricated SLMed 316L [12]. This 'hierarchically heterogeneous microstructure' is considered to attribute to the excellent mechanical performance of SLMed stainless steels with low porosity rates $[12,16,17]$. Meanwhile, a strong solidification $<100>$ texture is commonly found in SLMed stainless steels $[15,18]$, resulting in the mechanical property anisotropy [17].

Despite the successful implementation of SLM, the use of SLMed MSSs is not well investigated. A few research outcomes have been published regarding the effects of processing parameters on the microstructures and mechanical properties of direct laser-deposited (DLDed) MSSs [2, 18-20]. Martensitic and retained austenitic phases both exist in the as-fabricated state, while a small amount of eutectic delta ferrite that could be entirely eliminated after post-heat treatment could also be identified [19-21]. Furthermore, the presence of chromium carbides $\left(\mathrm{Cr}_{23} \mathrm{C}_{6}\right)$ could also be detected [20]. The mechanical property anisotropy of DLDed MSSs with a difference of $100 \mathrm{MPa}$ in the yield stress between the longitudinal and transverse directions could be identified [19], which could be attributed to the presence of sharp texture [18, 19]. Furthermore, the optimization of the processing strategy could help reduce the tensile property anisotropy [19].
Successful attempts on fabricating high-strength martensitic steels by using SLM have also been carried out, with their yield strength largely exceeding wrought materials [22-26]. The presence of a high dislocation density, a large number of grain boundaries and a heterogeneous microstructure in the as-fabricated SLMed MSSs was found attributed to this superior strength [24]. Chemical composition modification in SLMed MSSs, adding more $\mathrm{Nb}$ and Mo into the matrix for instance [27], could also contribute to the higher strength and retained ductility. However, the understanding of the microstructure and mechanical performance of SLMed MSSs is still limited, and the effects of the post-heat treatments on SLMed MSSs need further investigation.

In this study, the microstructure of an as-fabricated SLMed AISI 420 was investigated by detailed electron backscattered diffraction analysis to investigate the presence of retained austenite, martensite and carbides. Tensile property anisotropy with a significant difference between the ductility in the longitudinal and transverse directions could be identified in the as-fabricated SLMed AISI420. After a regular post-heat treatment including austenitizing and tempering, a fully martensitic microstructure was achieved, eliminating the tensile property anisotropy.

\section{Experimental}

\subsection{Material and Selective Laser Melting Process}

The raw material used for the SLM process was AISI420 powder with spherical morphology and the size of approximately 10-53 $\mu \mathrm{m}$ (Fig. 1). Some irregular-shaped and satellite powders could still be identified from the gas-atomized AISI420 powders (Fig. 1a). The SLM fabrication was carried out in a Renishaw AM250 with a $400 \mathrm{~W}$ pulse laser source by using
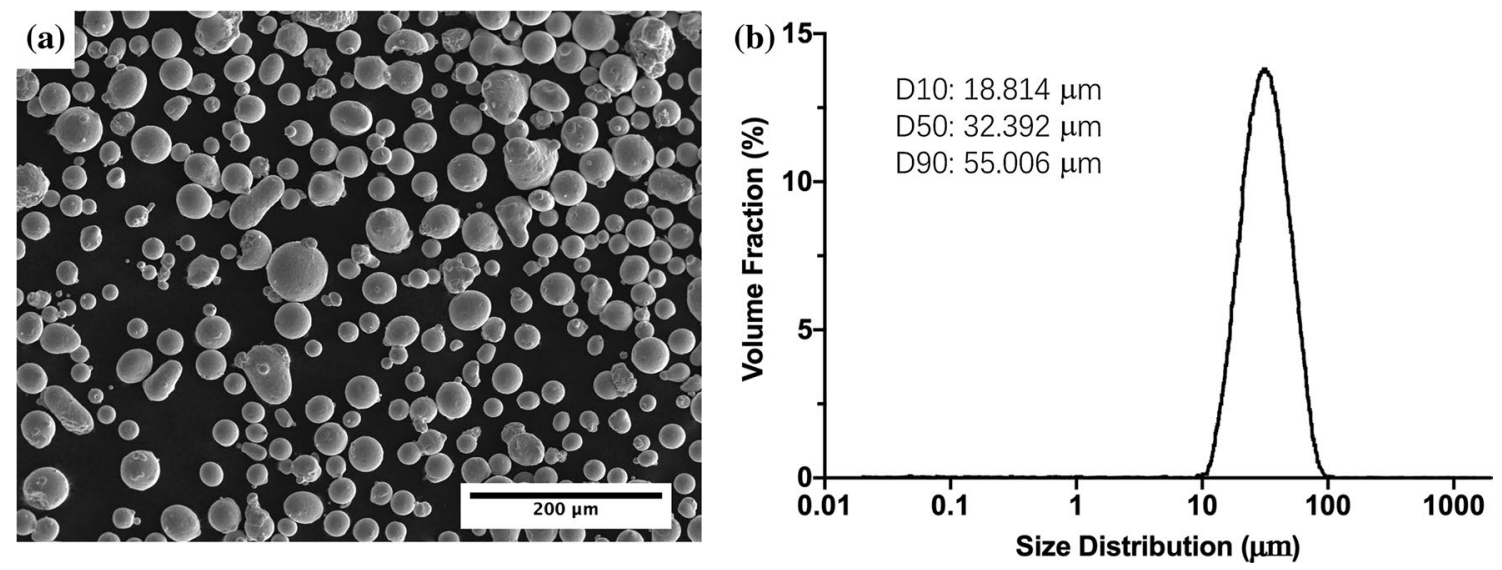

Fig. 1 a Secondary electron image of powders used for the SLM process in this study, b powder size distribution (including D10, D50 and D90) of the raw powders 
the parameters of laser power $200 \mathrm{~W}$, hatch distance $115 \mu \mathrm{m}$, layer thickness $30 \mu \mathrm{m}$, point distance $75 \mu \mathrm{m}$ and exposure time $110 \mu \mathrm{s}$ (with an equivalent laser speed $\sim 680 \mathrm{~mm} / \mathrm{s}$ ). The oxygen concentration was kept below 100 ppm during the printing process, and the scanning strategy with the laser scanning direction rotated by $67^{\circ}$ was used in this study. The volumetric energy density was estimated as $85.25 \mathrm{~J} / \mathrm{mm}^{3}$. Prior to this study, a relative density of $99.73 \%$ (measured by the Archimedes method) was already achieved via the parameter optimization. Furthermore, no significant difference between the compositions of powder and as-fabricated samples could be found, which were both within the specification of AISI 420 (Table 1). However, the Mn concentration of the as-fabricated sample was close to the upper limit of $1.0 \mathrm{wt} \%$ in the specification. A two-step post-heat treatment was carried out in a vacuum furnace. The first step was austenitizing treatment at 1273.15 $\mathrm{K}$ for $40 \mathrm{~min}$ followed by gas quenching, and the second step was tempering at $833.15 \mathrm{~K}$ for $180 \mathrm{~min}$ followed by gas cooling. A wrought AISI420 with the same post-heat treatment was used for comparison in this study.

\subsection{Tensile and Hardness Testing}

Brinell hardness measurements by using a load of $62.5 \mathrm{~kg}$ and a 2.5 -mm-diameter indent were used on ground samples. Three replicates (i.e. three samples) per condition were used for this measurement with six indentations made on each sample to obtain the average values. Tensile testing was carried out on a universal tensile testing machine using dogbone-shaped samples with the parallel section dimensions of $28 \mathrm{~mm} \times 5 \mathrm{~mm} \times 2 \mathrm{~mm}$ (Fig. 2), in accordance with the China testing standard GB/T228. A constant cross-head speed of $2 \mathrm{~mm} / \mathrm{min}$ was used for the tensile testing with three repeating tests per condition.

\subsection{Microstructure Characterization}

Metallurgical samples were first prepared by grinding and polishing, then etched by using a solution mixed with $50 \mathrm{ml}$ hydrochloric acid, $25 \mathrm{ml}$ nitric acid and $25 \mathrm{ml}$ water and characterized by using optical and electron microscopy. Backscattered electron micrographs were taken by using a fieldemission scanning electron microscope (FE-SEM) FEI Nova 450. Electron backscattered diffraction (EBSD) data were obtained by using FE-SEM JOEL JSM-7900F equipped with the EBSD detector from EDAX. Due to the finer microstructures in the as-fabricated state, the step size used for EBSD data acquisition was $0.13 \mu \mathrm{m}$, while the step size used for the data acquisition from heat-treated samples was $0.25 \mu \mathrm{m}$. Texture index $(\boldsymbol{J})$, a single parameter that integrates the crystallographic orientations of all grains [28-30], was used in this study to characterize the texture sharpness adequately. The texture index is 1 for a completely random orientation and $\infty$ (infinity) for a single crystal.

\section{Results}

\subsection{Mechanical Properties of the As-Fabricated and Heat-Treated AISI420}

Strong anisotropy of the hardness and tensile properties could be identified in as-fabricated SLMed AISI420 in both longitudinal $(\mathrm{L})$ and transverse $(\mathrm{T})$ directions, as revealed from the property summaries (Figs. 3, 4). The ductility of the as-fabricated samples tested in the longitudinal direction was very low, with only $1.25 \%$, while that of the samples tested in the transverse direction was much higher (6.8\%). Meanwhile, the difference in the tensile strength between longitudinal and transverse directions is relatively small (Fig. 4b). Due to the low ductility, the samples tested in the longitudinal direction failed before reaching the necking stage, which led to a smaller ultimate tensile stress (could be alternatively termed as 'fracture stress').

After the post-treatment, mechanical performance changed significantly. The Brinell hardness values of SLMed AISI420 in both longitudinal and transverse directions were 326.0, which was slightly higher than that of the wrought AISI420 after the same heat treatment (Fig. 3). The tensile property anisotropy was also fully eliminated after the
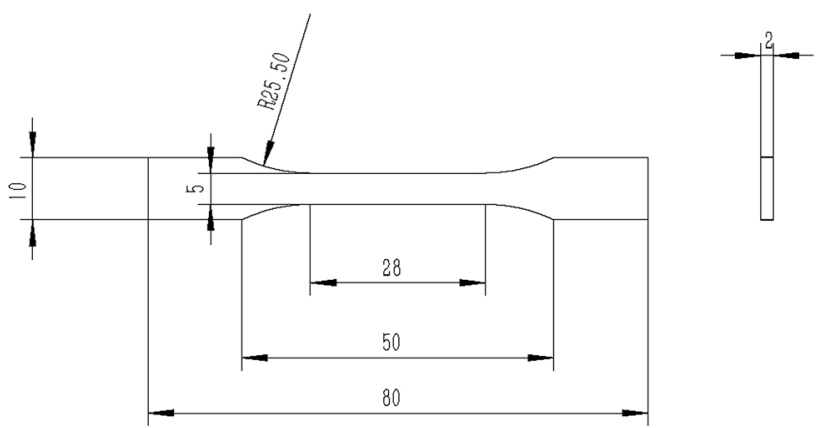

Fig. 2 Schematic drawing of the tensile testing sample used in this study
Table 1 Measured chemical compositions of as-received powder and as-fabricated sample (wt\%)

\begin{tabular}{|c|c|c|c|c|c|c|c|c|}
\hline Sample & & $\mathrm{C}$ & Mn & $\mathrm{Si}$ & $\mathrm{S}$ & $\mathrm{P}$ & $\mathrm{Cr}$ & $\mathrm{Fe}$ \\
\hline & Powder & 0.23 & 1.05 & 0.94 & 0.009 & 0.013 & 12.55 & Bal \\
\hline & Built sample & 0.21 & 0.98 & 0.95 & 0.006 & 0.020 & 12.72 & Bal \\
\hline
\end{tabular}




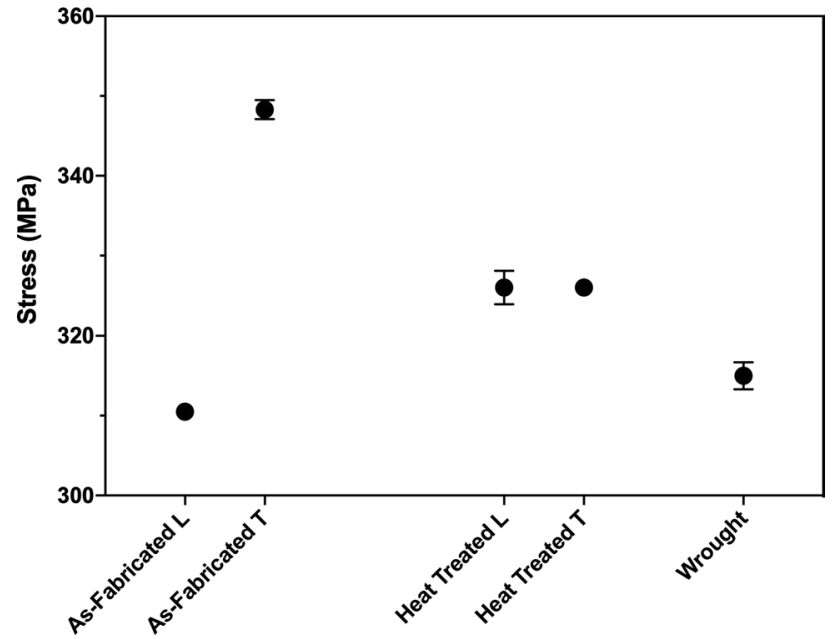

Fig. 3 Brinell hardness (with standard deviation as the error bars) of the as-fabricated and heat-treated samples in both longitudinal and transverse directions, and the wrought AISI420

post-treatment, while the ductility of both longitudinal and transverse samples increased significantly to more than $11 \%$, which was lower than that of the wrought AISI420 (Fig. 4). The proof stress also increased to around $870 \mathrm{MPa}$ with a small difference between the longitudinal and transverse directions, while the ultimate tensile stress dropped to approximately $1000 \mathrm{MPa}$ after the heat treatment, which was slightly higher than that of the wrought AISI420.

\subsection{Microstructure Characterization}

\subsubsection{Microstructure Characterization of As-Fabricated SLMed AISI420}

A dense microstructure with no noticeable large pores could be achieved by using the optimized SLM processing

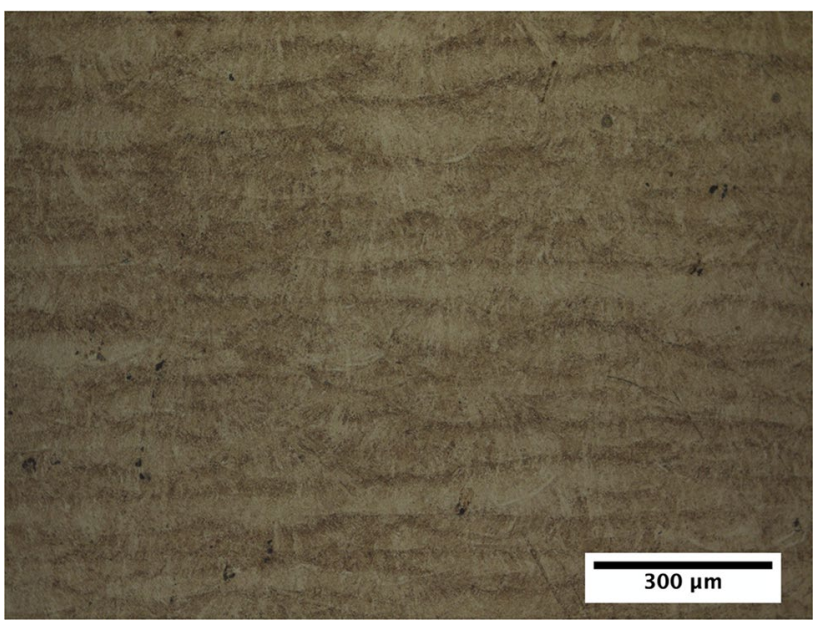

Fig. 5 Optical micrograph of as-fabricated sample taken in the longitudinal direction

parameters (Fig. 5). The deposition layer boundaries could be visually identified from the optical micrograph, while the microstructure that included grain morphologies and phase distributions was not visible. Fine particles, which were suspected as carbides embedded on the matrix with the contrast appearing as black, could be identified from the backscatter electron (BSE) micrographs in both longitudinal and transverse directions (Fig. 6a, b). The phase maps calculated from the detailed EBSD characterization showed the existence of approximately $30 \%$ of retained austenite in the as-fabricated state (Fig. 6c, d).

Microstructure with elongated columnar parent-austenitic grains was dominant in the longitudinal direction, while no obvious difference between the molten pool boundary and centre could be identified (Fig. 7a). Meanwhile, parent-austenitic grains with equiaxed morphologies instead of columnar morphologies could be found in the transverse direction
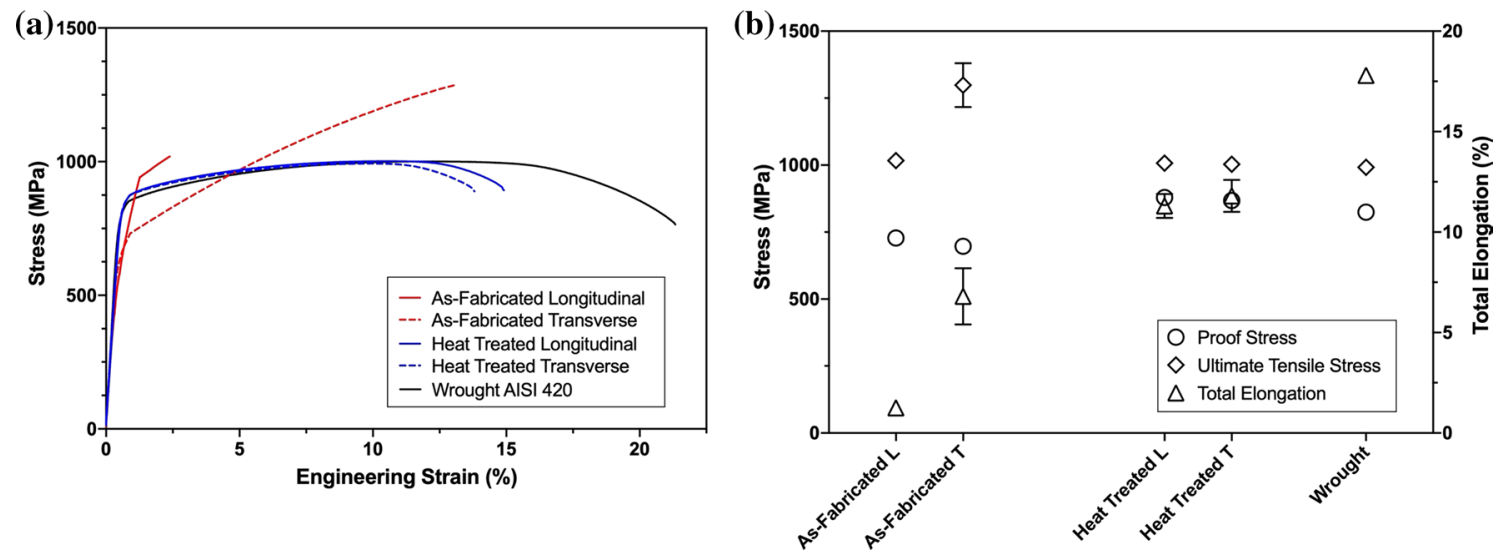

Fig. 4 a Representative tensile stress-strain curves of SLMed AISI420 in the two directions and wrought AISI420, b calculated tensile properties, which include $0.2 \%$ proof stress, ultimate tensile stress and total elongation, of AISI420 and wrought AISI420 
(Fig. 7b). The parent-austenitic grain morphologies in this as-fabricated SLMed AISI420 had similarity with those in SLMed stainless steels [17]. The martensitic texture was relatively weak with a texture index of only 1.62 , while the austenitic texture was stronger with a texture index of 3.02 (Fig. 8). Furthermore, the (001) poles of the austenitic phase were approximately $30^{\circ}$ off the longitudinal direction. Due to the rotation scanning strategy used in this study, the heat dissipation directions during the SLM process were not exactly longitudinal. Thus, the (001) crystallographic planes of the austenitic phase could be considered as aligned with the heat dissipation direction. This could certainly lead to the formation of solidification texture of the austenitic phase, which was already commonly reported in the SLMed austenitic stainless steels $[14,15]$.
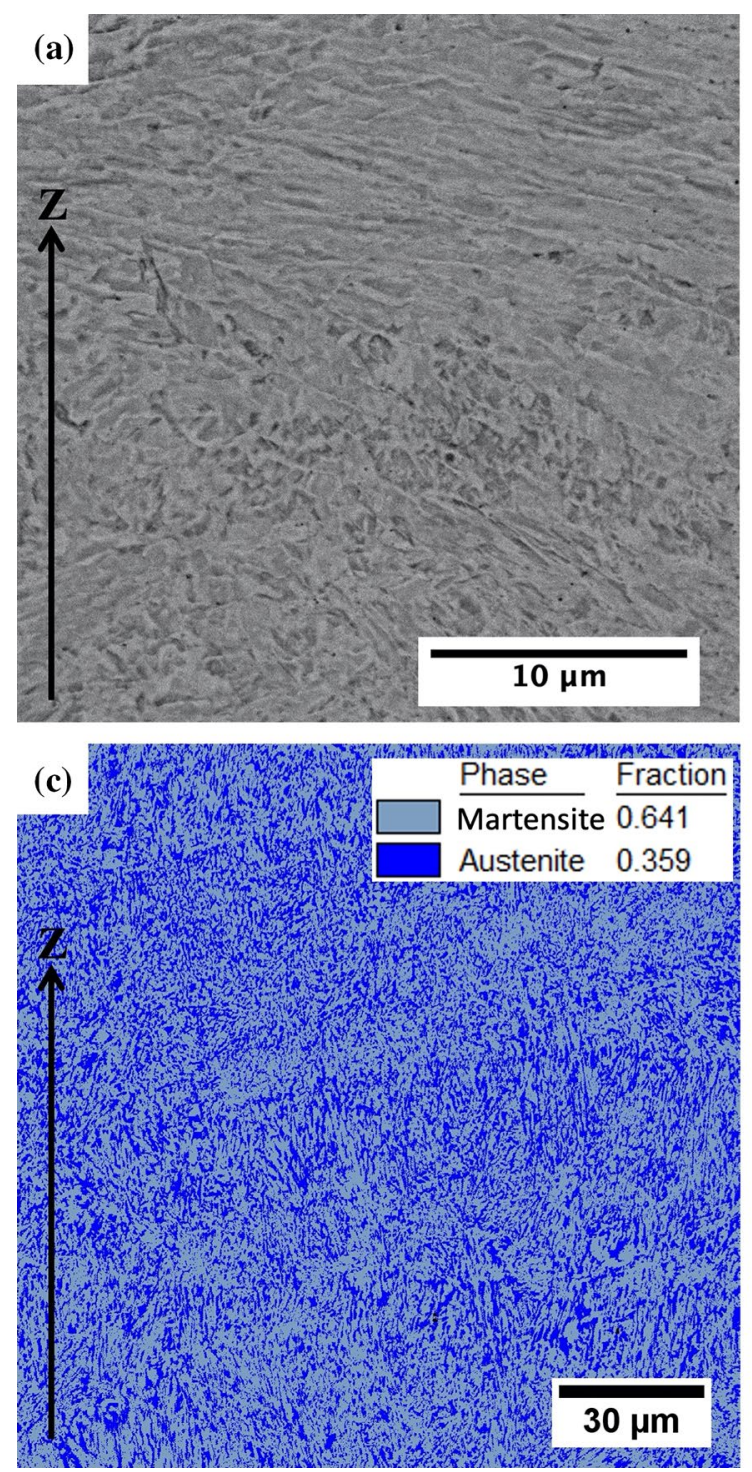

Furthermore, the detailed characterization of the two selected parent-austenitic grains showed that the orientation relationship between the transformed martensitic phase and the parent-austenitic phase was followed, as indicated by the alignment of the $\{110\}_{\text {martensite }}$ with $\{111\}$ austenite (Fig. 9). However, the exact orientation relationship for the austenite to martensite transformation (Kurdjumov-Sachs, Greninger-Troiano, Nishiyama-Wassermann and Bain relationships as the most commonly used $[31,32]$ ) could not be determined since further analysis is required.
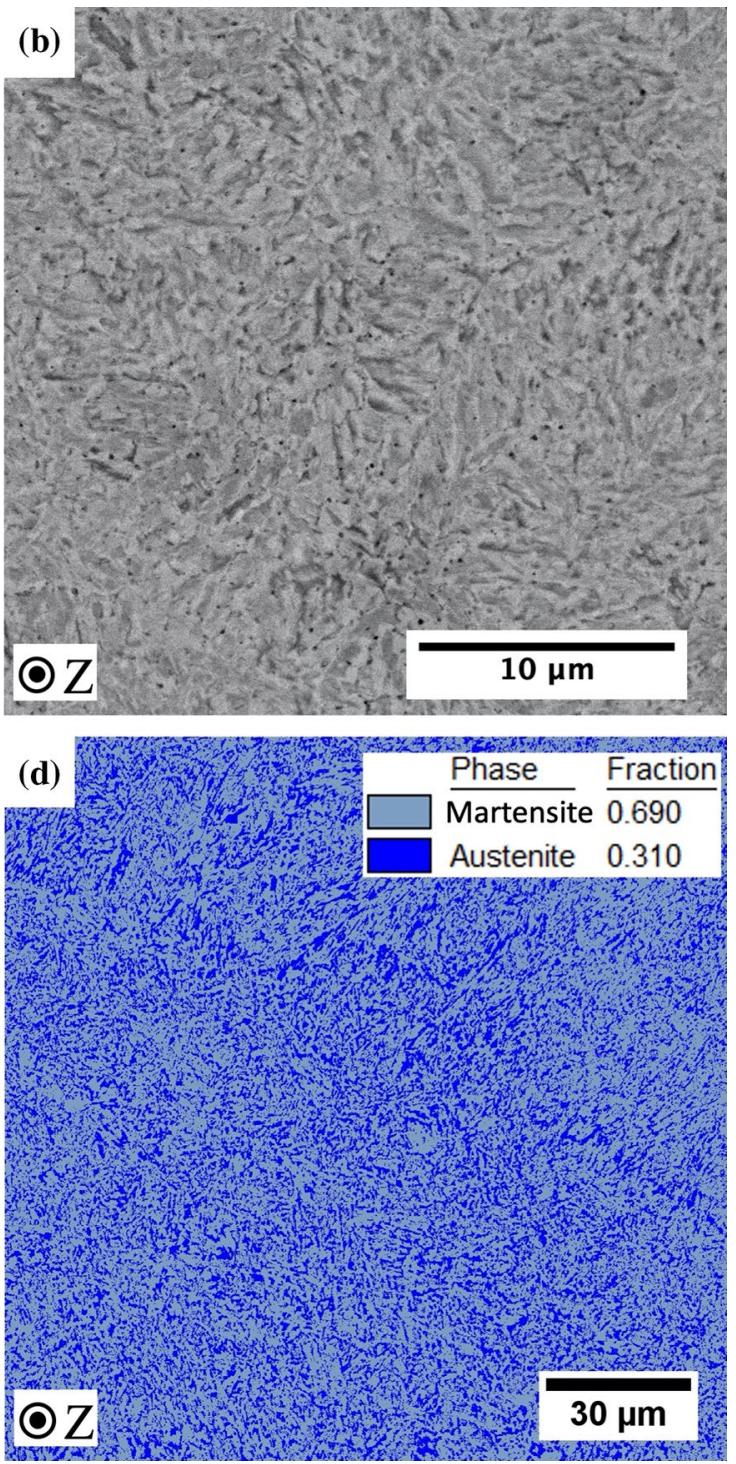

Fig. 6 Backscattered electron micrographs of as-fabricated samples taken at a longitudinal, $\mathbf{b}$ transverse directions, and phase maps with the area fractions of martensite and calculated from EBSD datasets of as-fabricated samples $\mathbf{c}$ longitudinal, $\mathbf{d}$ transverse directions 


\subsubsection{Microstructure Evolution After Heat Treatments in SLMed AISI420}

With the austenitizing and tempering treatments applied to the SLMed AISI420, coarse particles that were suspected $\mathrm{Cr}_{23} \mathrm{C}_{6}$ could be visibly identified in backscattered electron micrographs with no obvious segregation. (Some of the particles are marked by red arrows in Fig. 10a, b.) The presence of $\mathrm{Cr}_{23} \mathrm{C}_{6}$ carbides in both SLMed and direct laser deposited and then heat-treated AISI420 was confirmed in numerous publications [21, 33, 34]. A fully martensitic microstructure with the elimination of the austenitic phase was achieved and confirmed by the phase distribution maps (Fig. 10c, d).

The parent-austenitic grains were still visible in the inverse pole figure orientation maps (IPF OMs) of both longitudinal and transverse directions after the heat treatment, while their morphologies were clearly equiaxed (Fig. 11a, b). Furthermore, the sizes of these prior austenitic grains in heat-treated SLMed AISI420 were obviously smaller than those in the as-fabricated state. A very weak texture of the martensitic phase, with the texture index of 1.22 in the longitudinal and of 1.12 in the transverse direction, was formed after the heat treatment. However, the poles of the crystallographic planes $\{001\},\{110\}$ and $\{111\}$ still had some concentrations as revealed on the corresponding pole figures and aligned with the fabrication direction (Fig. 11c, d). This also indicated the transformation of the solidification austenitic texture during the heat treatment process.

Because both martensitic grains and retained austenitic grains were needle shaped, we used the grain widths calculated from the identified grains in the EBSD datasets to represent their morphologies. The grain morphologies on the longitudinal and transverse directions were consistent. Thus, only the microstructures in the longitudinal direction were calculated and compared (Fig. 12). In the as-fabricated state, the microstructure was relatively fine, with the average martensitic grain width of $0.71 \mu \mathrm{m}$ and the average austenitic grain width of $0.81 \mu \mathrm{m}$. Most of these identified grains
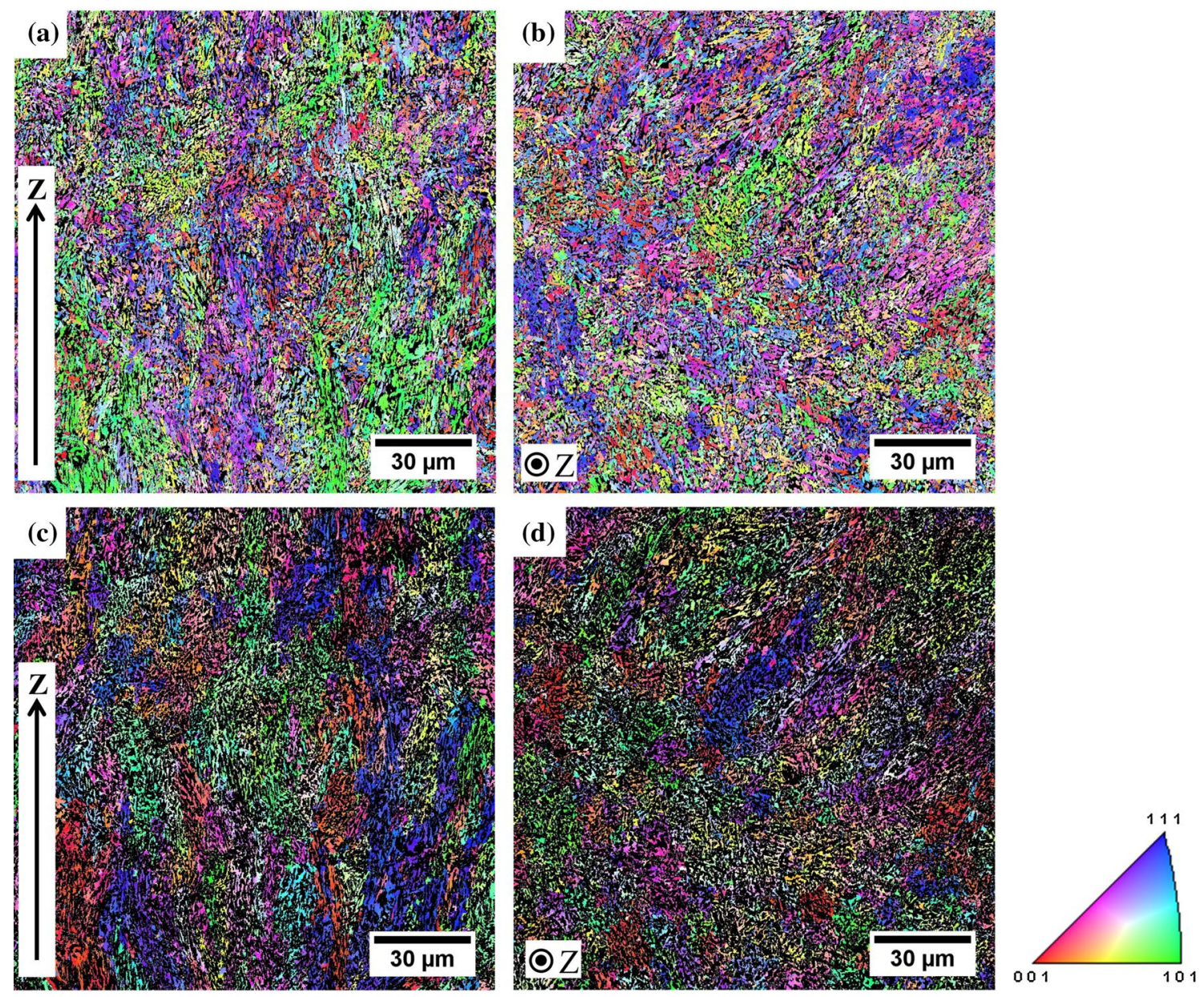

Fig. 7 Inverse pole figure orientation maps of martensitic phase on a longitudinal direction, b transverse direction of as-fabricated samples, with the black background austenitic phase, and inverse pole figure orientation maps of austenitic phase on $\mathbf{c}$ longitudinal direction, $\mathbf{d}$ transverse direction, with the black background martensitic phase 
have their widths less than $2 \mu \mathrm{m}$ (Fig. 12a). In contrast, the martensitic grains after the heat treatment, which were transformed from the austenitic grains during the quenching process, became much coarser with some of them more than $3 \mu \mathrm{m}$. However, the grain orientation spreads (GOS), which could be used to indicate the dislocation density [35], remained nearly constant after the heat treatment (Fig. 12b). Furthermore, most of the austenitic and martensitic grains had GOS values less than $2^{\circ}$, indicating the strain-free state in the as-fabricated state as well.

\section{Discussion}

A high-strength steel AISI420 fabricated by selective laser melting and treated with austenitizing and tempering heat treatments was investigated in this study. A tensile strength comparable with the wrought AISI420 was achieved after austenitizing and tempering treatments, which is lower than those reported in other SLMed AISI420 with tempering treatment $[22,36]$. A microstructure mixed with martensite and retained austenite was achieved in the as-fabricated state, while the presence of martensite was from the austenite transformation during the SLM process. The cooling rate within a molten pool $\left(\geq 5 \times 10^{4} \mathrm{~K} / \mathrm{s}\right.$ [6]) was significantly higher than those in the quenching process, which could favour the formation of martensite. However, the reheating in the heat-affected zone could reversely transform the martensite back to austenite. The reheating and cooling during the SLM process could lead to the cyclic phase transformation between austenite and martensite and retain the presence of austenite in the deposited AISI420. While the cooling rate of the fabricated AISI420 many layers below the molten pool is significantly lower than that within the molten pool and heat-affected zone, the presence of austenite could be retained in the fabricated AISI420, which is also consistent with the published results [36].

The solidification texture, which is the alignment of $\{001\}$ crystallographic planes of the austenite with the fabrication direction [14], could still be identified in the asfabricated state, while the texture intensity is relatively low with the index of 3.02. The martensite transformed from the parent austenite also formed a texture. However, this transformed martensitic texture is weaker than the austenitic texture due to various martensitic crystallographic variants (up to 24 variants [31]) during the phase transformation process. Furthermore, the presence of the texture leads to mechanical property anisotropy, as revealed by the hardness and tensile property difference of as-fabricated longitudinal and transverse samples. However, the ductility of the longitudinal tensile samples is significantly lower than that of the transverse tensile samples, which could also be found in other published results $[27,36]$. The porosity of this SLMed AISI420 is very low with the relative density measured as (a)

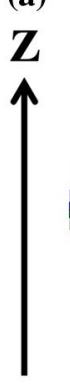

001

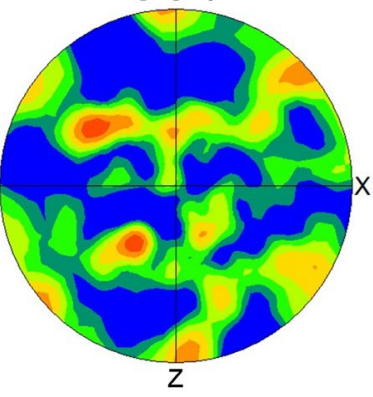

(b)

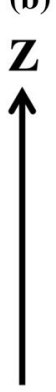

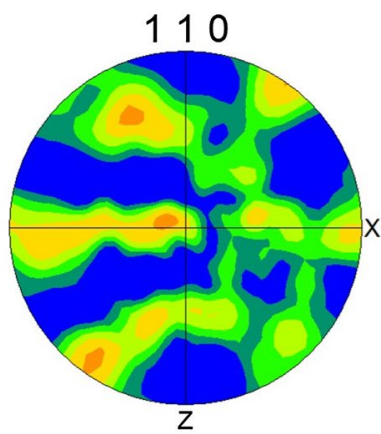

Z

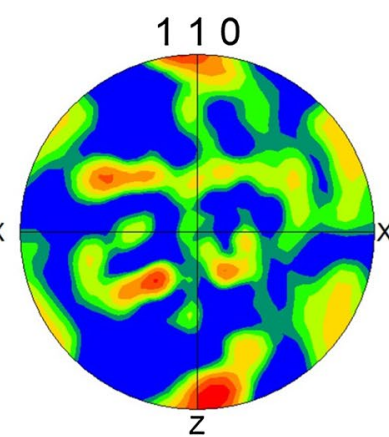

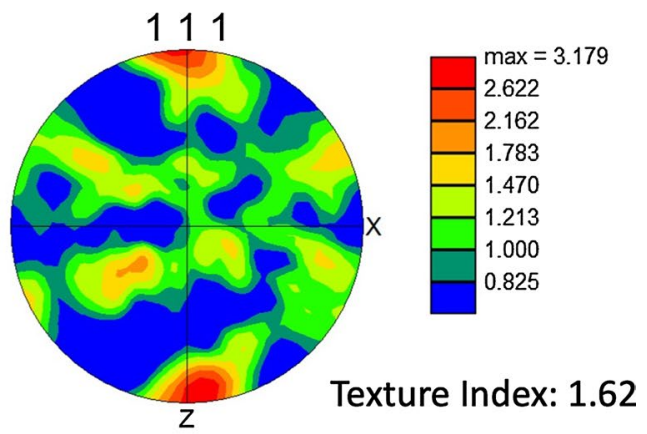

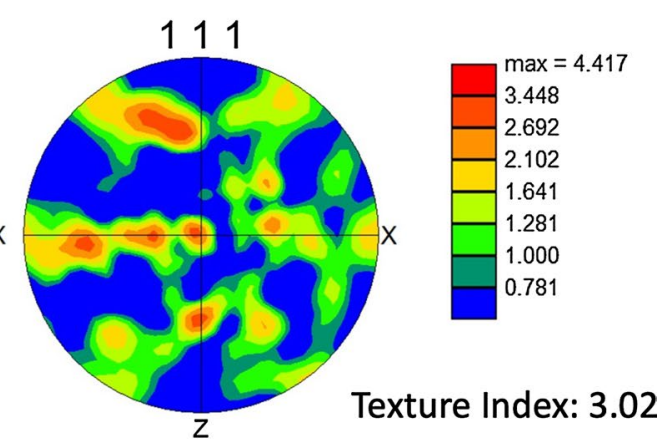

Fig. 8 Pole figures of a martensite, $\mathbf{b}$ austenite with their texture indexes in the longitudinal direction of the as-fabricated samples, with the building direction $(Z)$ marked next to the pole figures 

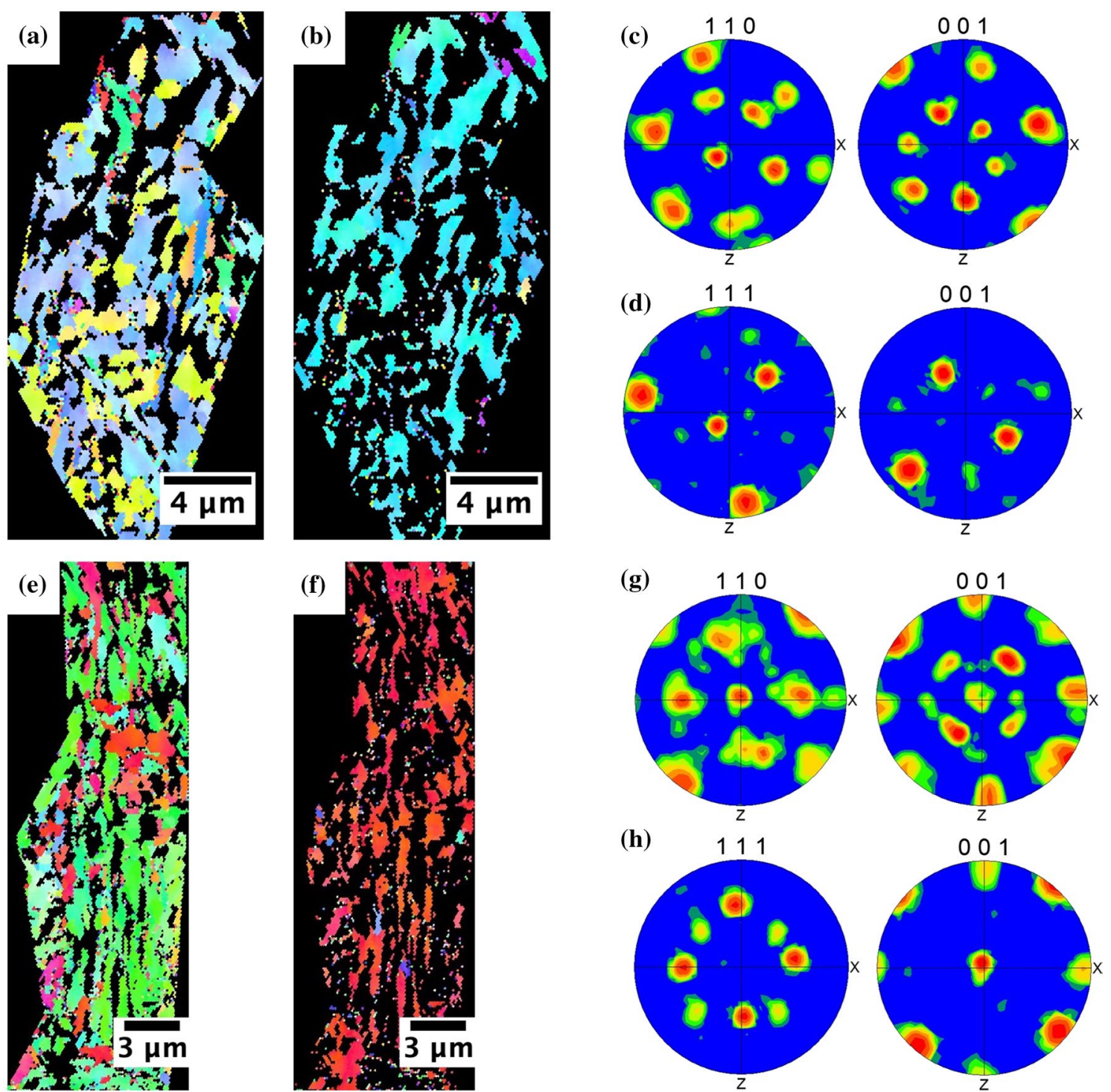

Fig. 9 IPF OMs of $\mathbf{a}, \mathbf{e}$ martensitic phases, $\mathbf{b}, \mathbf{f}$ austenitic phases in the two selected parent-austenitic grains, and the corresponding pole figures of $\mathbf{c}, \mathbf{g}$ martensitic phases, $\mathbf{d}, \mathbf{h}$ austenitic phases

99.73\% and is hardly the cause for the low ductility of asfabricated longitudinal samples. Furthermore, the GOS analysis of the as-fabricated SLMed AISI420, which shows a strain-free state, indicates that the residual stress may not be high. Further investigation may be needed to explain the low ductility of the longitudinal tensile samples.

Furthermore, the post-heat treatment that includes austenitizing and tempering process alters the microstructure entirely and improves the tensile performance. The microstructure is fully transformed to martensite after the quenching from the austenitizing temperature, and the prior austenitic grains become equiaxed. Meanwhile, coarse $\mathrm{Cr}_{23} \mathrm{C}_{6}$ carbides, which were commonly reported in heat-treated additive manufactured AISI420 [21, 33, 34], could be easily identified on the martensitic matrix. Meanwhile, the texture of the heat-treated SLMed AISI420 is close to random, with the texture index of approximately 1.2 , which leads to the elimination of mechanical property anisotropy. The hardness and tensile properties of heat-treated SLMed AISI420 tested in both directions are identical, comparable to the wrought AISI420 after the same heat treatment. The ductility of the heat-treated SLMed AISI420 also correspondingly improves significantly to $11 \%$.

\section{Conclusions}

The microstructures and mechanical performance of a highstrength martensitic steel AISI420 fabricated by selective laser melting were investigated and compared to wrought 

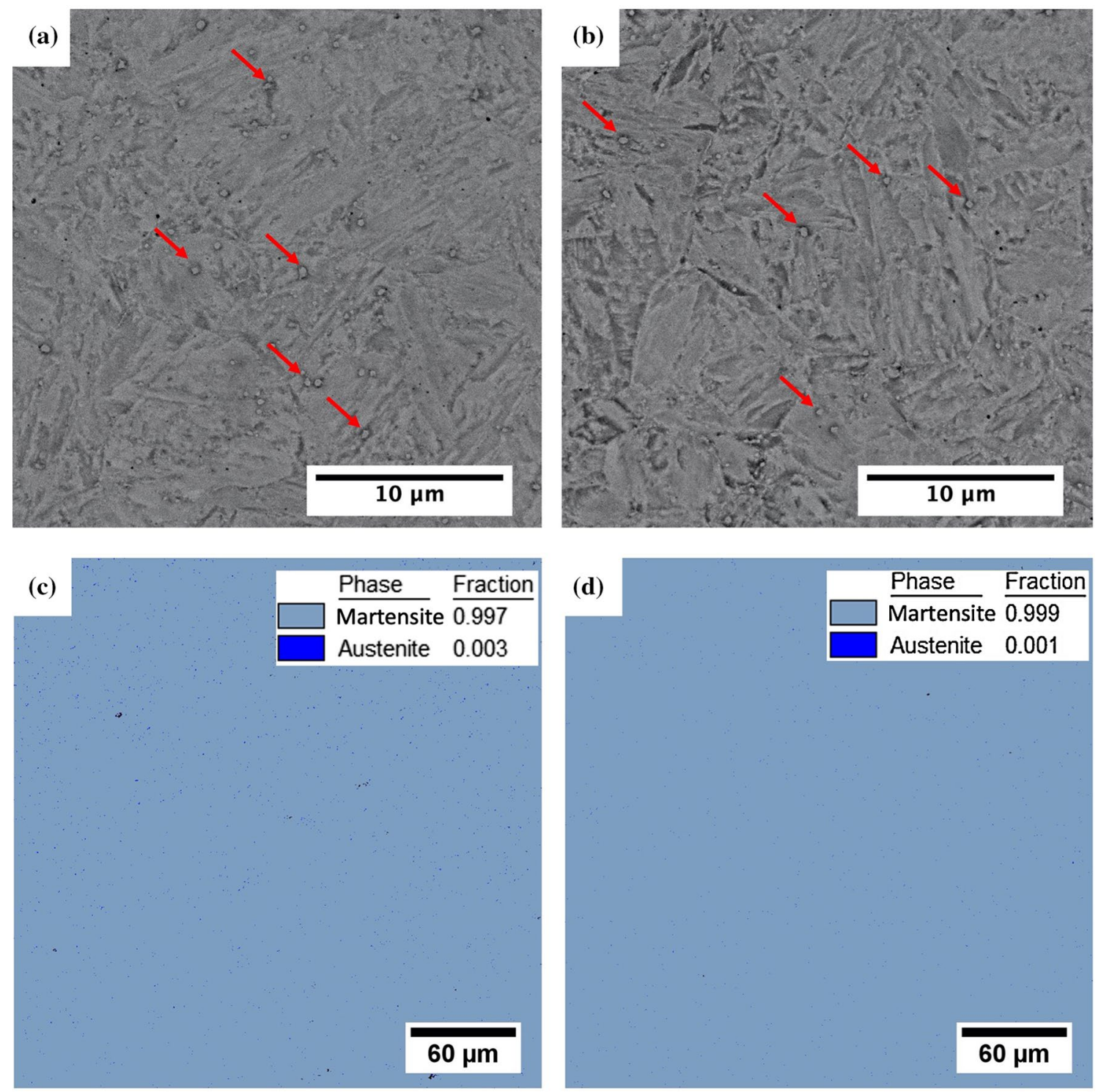

Fig. 10 Backscattered electron images of heat-treated SLMed AISI420 taken at a longitudinal, b transverse directions; and phase maps with the area fractions of martensite and calculated from EBSD datasets of as-fabricated samples $\mathbf{c}$ longitudinal, $\mathbf{d}$ transverse directions

AISI420 in this study. Through the detailed characterization into the microstructures of as-fabricated and heat-treated SLMed AISI420, the following conclusions can be drawn:

1. Retained austenite with the amount more than $30 \%$ could be identified in as-fabricated SLMed AISI420. The martensite transformed from austenite obviously followed the orientation relationship, while its texture was slightly weaker than the solidification texture in the austenite formed during the SLM process.

2. The two-step post-heat treatment, including austenitizing and tempering, transformed the microstructure into full martensite with grain coarsening and the formation of $\mathrm{Cr}_{23} \mathrm{C}_{6}$ particles. The texture was significantly weak- ened after this heat treatment, with its intensity close to random.

3. The as-fabricated SLMed AISI420 had a strong mechanical property anisotropy in both strength and ductility. The difference between the tensile strength of longitudinal and transverse directions was attributed to the presence of texture. With the texture weakened after the post-heat treatment, the ductility of SLMed AISI420 increased significantly, and the tensile property anisotropy eliminated. The tensile performance of SLMed AISI420 in this study was comparable with the wrought AISI420 after the same heat treatment. 

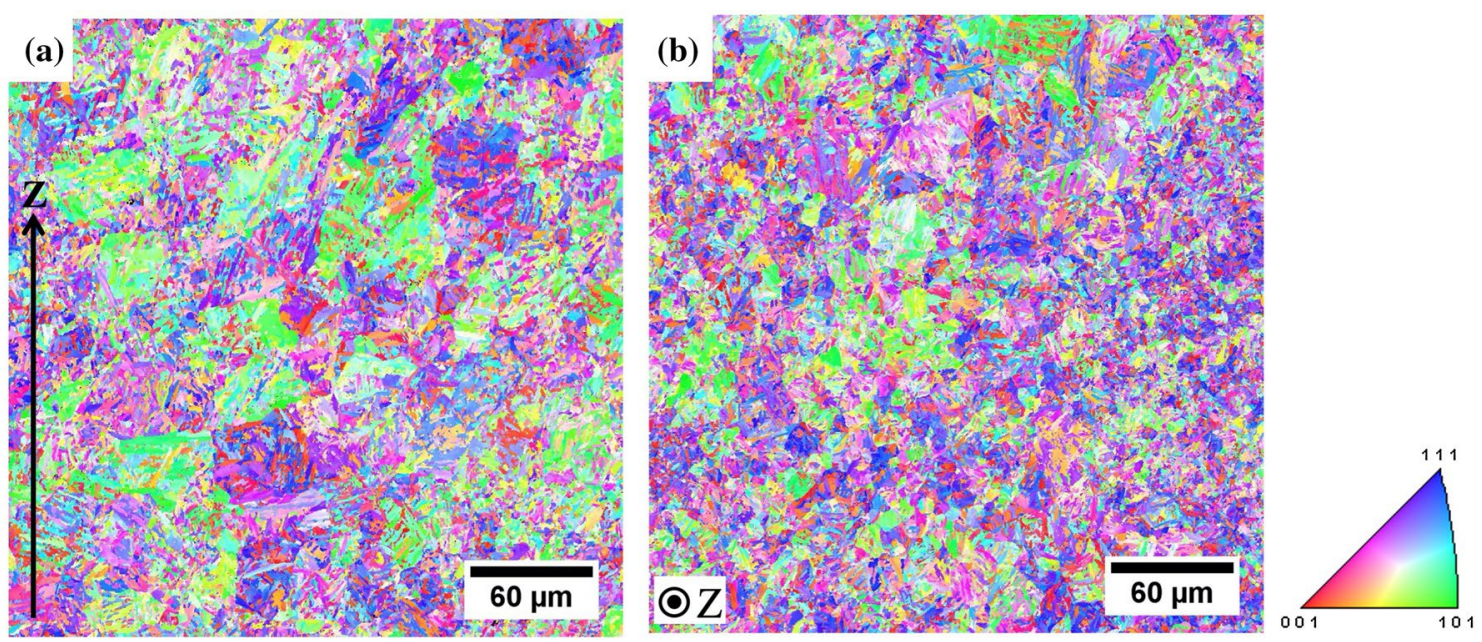

(c)

001

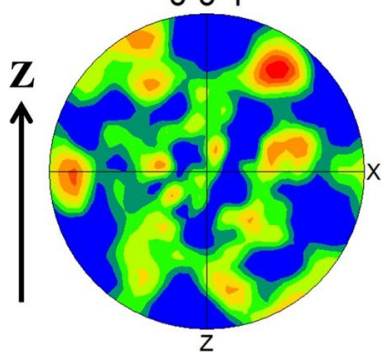

(d)

001

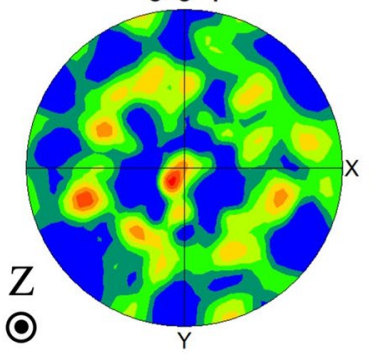

110

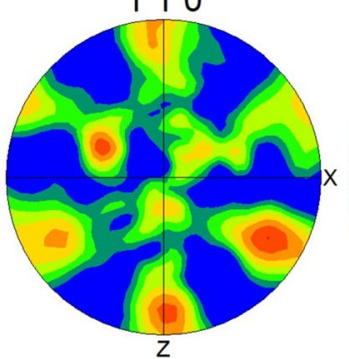

110

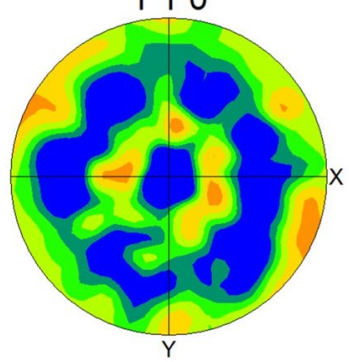

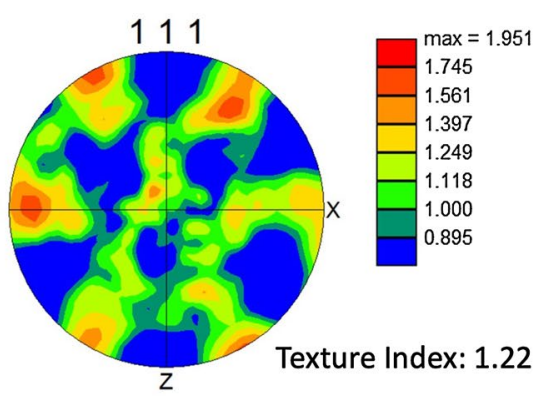

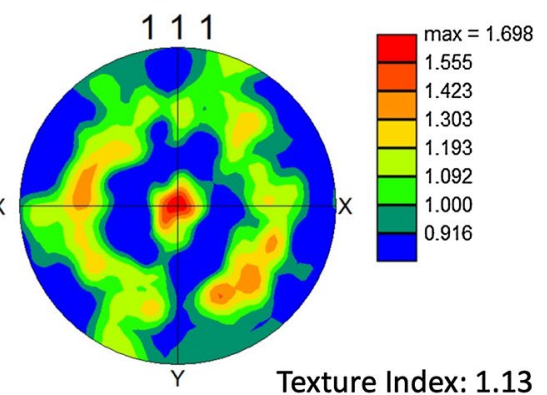

Fig. 11 IPF OMs of heat-treated SLMed AISI420 on a longitudinal, b transverse directions, and their corresponding pole figures on $\mathbf{c}$ longitudinal, $\mathbf{d}$ transverse directions with the texture indexes labelled
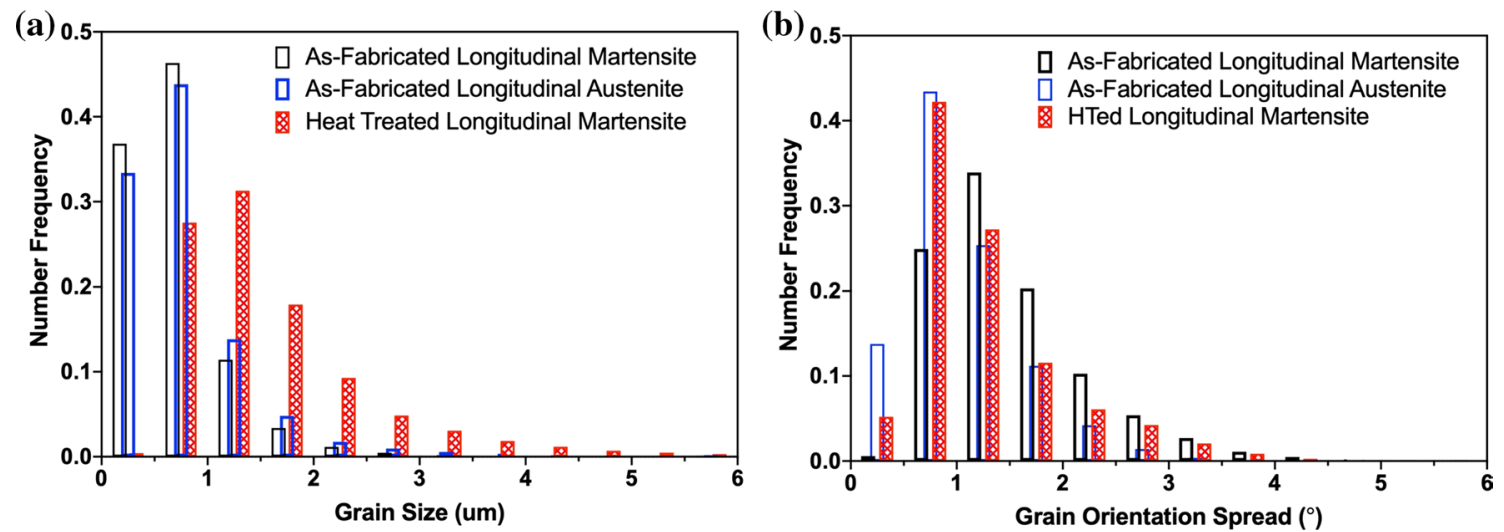

Fig. 12 a Grain size distribution, b grain orientation spread of austenitic grains in the as-fabricated sample and martensitic grains in both asfabricated and heat-treated samples. Only the calculated results on longitudinal direction, which were also representative of those on transverse direction, were plotted 
Acknowledgements This work was supported by the National Key R\&D Program of China (Grant No. 2018YFB1106100), the Shanghai Science and Technology Talents Program Fund (No. 19XD1431600) and the Shanghai Research Center of Complex Metal Parts by Additive Manufacturing (No. 14DZ2253600).

\section{References}

[1] S.K. Bonagani, V. Bathula, V. Kain, Corros. Sci. 131, 340 (2018)

[2] M. Erdem, M. Altuğ, M. Karabulut, Int. J. Adv. Manuf. Technol. 85, 481 (2016)

[3] A. Rajasekhar, Int. J. Sci. Eng. Res. 6, 547 (2015)

[4] X. Zhao, Q. Wei, B. Song, Y. Liu, X. Luo, S. Wen, Y. Shi, Mater. Manuf. Process. 30, 1283 (2015)

[5] C.Y. Yap, C.K. Chua, Z.L. Dong, Z.H. Liu, D.Q. Zhang, L.E. Loh, S.L. Sing, Appl. Phys. Rev. 2, 041101 (2015)

[6] T. DebRoy, H.L. Wei, J.S. Zuback, T. Mukherjee, J.W. Elmer, J.O. Milewski, A.M. Beese, A. Wilson-Heid, A. De, W. Zhang, Prog. Mater. Sci. 92, 112 (2018)

[7] Z. Chen, X. Wu, D. Tomus, C.H.J. Davies, Addit. Manuf. 21, 91 (2018)

[8] J.H. Rao, Y. Zhang, A. Huang, X. Wu, K. Zhang, Int. J. Fatigue 182, 105215 (2019)

[9] J.H. Rao, Y. Zhang, K. Zhang, X. Wu, A. Huang, Mater. Des. 182, 108005 (2019)

[10] W. Xu, M. Brandt, S. Sun, J. Elambasseril, Q. Liu, K. Latham, K. Xia, M. Qian, Acta Mater. 85, 74 (2015)

[11] D. Zhang, D. Qiu, M.A. Gibson, Y. Zheng, H.L. Fraser, D.H. Stjohn, M.A. Easton, Nature 576, 91 (2019)

[12] Y.M. Wang, T. Voisin, J.T. McKeown, J. Ye, N.P. Calta, Z. Li, Z. Zeng, Y. Zhang, W. Chen, T.T. Roehling, R.T. Ott, M.K. Santala, P.J. Depond, M.J. Matthews, A.V. Hamza, T. Zhu, Nat. Mater. 17, 63 (2018)

[13] D. Herzog, V. Seyda, E. Wycisk, C. Emmelmann, Acta Mater. 117, 371 (2016)

[14] P. Krakhmalev, G. Fredriksson, K. Svensson, I. Yadroitsev, I. Yadroitsava, M. Thuvander, R. Peng, Metals (Basel) 8, 643 (2018)

[15] Z. Sun, X. Tan, S.B. Tor, C.K. Chua, NPG Asia Mater. 10, 127 (2018)

[16] G.T. Gray, V. Livescu, P.A. Rigg, C.P. Trujillo, C.M. Cady, S.R. Chen, J.S. Carpenter, T.J. Lienert, S.J. Fensin, Acta Mater. 138, 140 (2017)
[17] J. Hou, W. Chen, Z. Chen, K. Zhang, A. Huang, J. Mater. Sci. Technol. 48, 63 (2020)

[18] F. Khodabakhshi, M.H. Farshidianfar, A.P. Gerlich, M. Nosko, V. Trembošová, A. Khajepour, Addit. Manuf. 31, 100915 (2020)

[19] M.K. Alam, M. Mehdi, R.J. Urbanic, A. Edrisy, Mater. Sci. Eng. A 773, 138815 (2020)

[20] M.K. Alam, A. Edrisy, J. Urbanic, J. Pineault, J. Mater. Eng. Perform. 26, 1076 (2017)

[21] M.K. Alam, A. Edrisy, J. Urbanic, Metall. Mater. Trans. A Phys. Metall. Mater. Sci. 50, 2495 (2019)

[22] K. Saeidi, D.L. Zapata, F. Lofaj, L. Kvetkova, J. Olsen, Z. Shen, F. Akhtar, Addit. Manuf. 29, 100803 (2019)

[23] R. Seede, D. Shoukr, B. Zhang, A. Whitt, S. Gibbons, P. Flater, A. Elwany, R. Arroyave, I. Karaman, Acta Mater. 186, 199 (2020)

[24] X. Li, Y.H. Tan, H.J. Willy, P. Wang, W. Lu, M. Cagirici, C.Y.A. Ong, T.S. Herng, J. Wei, J. Ding, Mater. Des. 178, 107881 (2019)

[25] E. Jelis, M. Clemente, S. Kerwien, N.M. Ravindra, M.R. Hespos, JOM 67, 582 (2015)

[26] W. Wang, S. Kelly, JOM 68, 869 (2016)

[27] S.D. Nath, E. Clinning, G. Gupta, V. Wuelfrath-Poirier, G. L'Espérance, O. Gulsoy, M. Kearns, S.V. Atre, Addit. Manuf. 28, $682(2019)$

[28] K. Zhang, K.V. Yang, A. Huang, X. Wu, C.H.J. Davies, Int. J. Fatigue 80, 288 (2015)

[29] H.J. Bunge, P.R. Morris, Texture Analysis in Materials Science: Mathematical Methods, 2nd edn. (Butterworths, London, 1982), p. 137

[30] V. Randle, O. Engler, Introduction to Texture Analysis: Macrotexture, Microtexture and Orientation Mapping, 2nd edn. (CRC Press, Boca Raton, 2010), pp. 288-291

[31] J.G. Back, G. Engberg, Materials (Basel) 10, 453 (2017)

[32] P.P. Suikkanen, C. Cayron, A.J. DeArdo, L.P. Karjalainen, J. Mater. Sci. Technol. 27, 920 (2011)

[33] J.Y. Chen, L. Xue, S.H. Wang, Microstructure characterization of laser-consolidated AISI 420 stainless steel. Paper Presented at the International Symposium on Materials Engineering for Structural Applications, Pittsburgh, Pennsylvania, 5-9 October 2008

[34] P. Krakhmalev, I. Yadroitsava, G. Fredriksson, I. Yadroitsev, Mater. Des. 87, 380 (2015)

[35] A. Hadadzadeh, F. Mokdad, M.A. Wells, D.L. Chen, Mater. Sci. Eng. A 709, 285 (2018)

[36] S.D. Nath, H. Irrinki, G. Gupta, M. Kearns, O. Gulsoy, S. Atre, Powder Technol. 343, 738 (2019) 